\title{
Lifetime injury prevention: The sport profile model ${ }^{*}$
}

\author{
N Webborn \\ University of Brighton, Sussex Centre for Sport and Exercise Medicine, Sportswise Limited, The Welkin, Eastbourne BN20 7SN, UK \\ N Webborn
}

Corresponding author: $N$ Webborn (nickwebborn@sportswise.org.uk)

\begin{abstract}
Participation in sporting activities carries an injury risk. Conversely, the increased awareness that physical inactivity is a major risk factor for disease has led government agencies and the medical community to encourage increased levels of physical activity. Many people will achieve this through participation in sport. Injury inevitably leads to a reduction in participation on a temporary or permanent basis, but the injury experience may also influence the lifelong physical activity behaviour. Few studies adequately examine the possible long-term consequences of sport participation after the competitive period has been completed, but by understanding the patterns of injuries in different sports one test can develop strategies to prevent and better manage the conditions that occur and promote lifelong physical activity. There is a need to develop models of understanding of injury risk at different life phases and levels of participation in a specific sport. The risk assessment of sport participation has to be relevant to a particular sport, the level of participation, skill, age and potential future health consequences. This article describes a sport-specific model which will improve guidance for coaches and healthcare professionals. It poses questions for sports physicians, healthcare providers, educators and for governing bodies of sports to address in a systematic fashion. Additionally the governing body, as an employer, will need to meet the requirements for risk assessment for professional sport and its ethical responsibility to the athlete.
\end{abstract}

S Afr J SM 2012;24(4):117-121. DOI:10.7196/SAJSM.356

Participation in sporting activities carries an injury risk. ${ }^{1,2}$ Conversely, the increased awareness that physical inactivity is a major risk factor for disease has led the government agencies and the medical community to encourage increased levels of physical activity. ${ }^{3,4}$ Many people will achieve this through participation in a sport. The consequence of increased participation in a sport is an increase in the musculoskeletal injury. ${ }^{5}$ The injury inevitably leads to a reduction in the participation on a temporary or on a permanent basis, but the injury experience may also influence lifelong physical activity behaviour. $^{6-8}$ By understanding the patterns of injuries in different sports, we can develop strategies to prevent and better manage the conditions that occur and promote lifelong physical activity.

For funded athletes in elite sport in the UK, and for professional sportsmen, the sport is their occupation, their means of financial support. Their sporting career may also determine their financial future. This creates wider implications for injury prevention with regard to the roles and responsibilities of sports' governing bodies. There is an obligation for any employer to assess the health and safety in the workplace. An employee who has been exposed to a health risk during their period of employment has a justifiable right to know what sort of risk they are exposing themselves to and what are the potential longterm consequences (LTCs) to their health of that employment. From the perspective of the Health and Safety Executive, it is about reducing the risk to 'As Low As Reasonably Practicable.' The concept of 'reasonably practicable' lies at the heart of the British health and safety system and requires that an assessment must be made by the employer in which the quantum of risk is placed on one scale and the sacrifice involved in the measures necessary for averting the risk (whether in money, time or trouble) is placed in the other. Can sport employers automatically

* This article was reproduced with permission from the BMJ Group. It was first published in the British Journal of Sports Medicine 2012;46:193-197 (originally published online 4 January 2012). assume the concept of 'Volenti non fit injuria' (Latin: 'to a willing person, no injury is done') because athletes willingly participate though they were unaware of the potential consequences of participation? The concept is based on the person accepting and being aware of the risks inherent in that event, so that they cannot later have an injury or seek compensation for it. How can we reasonably expect any individual to make a considered judgement if the assessment of risk to health has not been made by the governing body? The evidence for the increased risk of knee and hip osteoarthritis in former professional soccer players is convincing, but are the players informed of this known risk? ${ }^{10-14}$ Should athletes have to accept long-term health consequences as 'part of the game' if there were preventive measures that could have been taken or if they were not informed of the risk?

Sports injury surveillance aims to reduce the risk of injury through identifying the size and severity of injury problems, by understanding the causes and mechanisms, and then by introducing preventive measures to attempt to reduce those risks. The model of van Mechelen is widely accepted as a good model of injury prevention. ${ }^{15}$ It works very well in assessing a particular situation in a sport, but we must be mindful that we also need to consider age, skill, experience and the competitive level of the participants, and not apply the results of such a survey equally to all situations for that sport. Injury surveillance is a complex issue given the nature of injury causation related to multiple factors, including, for example, the too early return to play from a preceding injury, described as the 'recursive nature of risk and causation. ${ }^{16,17}$ The Fédération Internationale de Football Association (FIFA) and Union of European Football Associations (UEFA) are making efforts through collaborative research and the FIFA Medical and Research Centres (F-MARC) to identify the frequency and characteristics of injury with a view to developing injury prevention strategies. ${ }^{18-20}$ The Rugby Football Union has also instituted injury surveillance in professional rugby, ${ }^{21-25}$ but this is solely at an elite level and as yet there is no long- 
term follow-up. Few studies adequately examine the possible LTCs of sport participation after the competitive period has been completed. ${ }^{26}$

To more usefully develop injury prevention that is sport-specific, the governing bodies and researchers need to consider a lifetime injury prevention model that takes into account a number of different factors because the strategies employed for prevention may be different at different stages of an athlete's career. Consequently, in the lifetime of a competitive athlete, we need to consider a number of different factors when performing injury surveillance if we are to address the risks across the full range of a sport's participants.

\section{Age}

\section{Growth-related injuries}

Injuries that occur in the immature skeleton produce different pathologies than in the adult skeleton. Bone growth precedes muscle, tendon and neural lengthening and consequently young sportspersons become neuromuscularly tight during peak growth spurts. This can result in different responses to acute and overuse injuries. However, this often tends to coincide with high levels of sport participation when there may also be an intense competition for the selection for sporting excellence; for example, academy selection. Injuries occurring at this time may limit the progression into a full-competitive career. Understanding the risk factors implicated in injuries in this age group would particularly be relevant to the sport academy setting. It is not just about the significant investment in these young players, injury prevention is also important to enable continued physical activity for life. ${ }^{27}$ Identifying the most common injuries that stop young players achieving their potential, and trying to prevent them, is a responsible healthcare and cost-effective for club and the healthcare system.

\section{Adult-onset injury}

Many people develop their sporting interest later in life. Maybe they were not the talented ones at school age, or were not given the opportunity or environment to develop within a structured system. Once they become independent adults, they may choose a sporting activity with little experience in training practices, equipment choices or coaching. The mature sportsman has different patterns of injury. For example, the rupture of the Achilles tendon occurs most frequently from 30 to 39 years, which is not the time of maximum sport participation, but we do not understand why this occurs at this time. ${ }^{28}$

In the older adult, progressing sarcopaenia and disuse atrophy may not just reflect the natural ageing process but be a consequence of a reduction in the physical activity. This may influence injury risk in the older adult. ${ }^{29,30}$ When people reach the age of retirement, they may have the time and the finance to take up activities they did not do in their working life. Little is known about this age group, but we need to preserve the ability to maintain an active lifestyle to minimise the health risks of sedentary behaviours. Do the injuries that occur in a particular sport in this older age group differ between those who have been active across their lifetime and those who have not? Does this mean that we need different prevention and treatment strategies across this group? Understanding that different injuries may occur in different age groups is important for athlete and coach education, and injury management.

\section{Skill acquisition injuries (SAIs)}

Athletes are susceptible to certain injury patterns in their sport as a consequence of the biomechanical requirements of that sport. In order to become technically proficient, they need to acquire the skills of their sport through repeated practice. We all have to go through a period of learning and at this point are likely to be vulnerable to injury, irrespective of our age, while we develop the mechanical efficiency for injury resilience. ${ }^{31}$ Good coaching is integral to that process but not everyone is exposed to that benefit. Across our lifetime, we may start and stop many sports or activities, and at each point of learning the new skill we become vulnerable to different injury types. We need also to be aware that SAIs can occur in mature athletes and not just the young, as many people take up different sports in later life. Consequently, we need to be able to distinguish age-related factors from skill acquisition factors in good sports injury surveillance. It is also not uncommon in the present times for athletes to change sport even at an elite level (e.g. Rebecca Romero - Great Britain rowing to cycling, Sarah Storey - Paralympic swimming to cycling). While these athletes will have the knowledge of how to be an elite athlete, they still need to acquire the technical skill and experience for the new sport. During this period, they may be more vulnerable to injury even though performing at an elite level.

The level of skill is also important. For example, the top-level tennis player does not regularly have a 'tennis elbow', unlike the beginner or technically poor exponent of the sport. ${ }^{32}$ However, each elite athlete has gone through a learning phase of acquiring the skills of their sport. Faulty technique, poor conditioning, recovery or training practices may lead to certain injury patterns which may stop the athlete progressing in the sport. Consequently, the skill level is an important risk factor and may determine the type of injury incurred when playing the same sport. In cricket, the high incidence of spondylitis in young cricket bowlers prompted the studies of the technical action. The 'front-on' versus 'side-on' versus 'mixed' bowling actions were considered, but many factors were identified making it difficult to ascertain which were the most significant. ${ }^{33-36}$

\section{Performance-related injuries}

In an elite sport, much of our attention is focused on returning the athlete to the field of play as soon as possible and published research in an elite sport is less common. ${ }^{19}$ This may be for the reasons of data protection or because of the relatively small sample sizes, but understanding why our top athletes become injured, and finding ways to prevent this, is important. The cost of an expensive athlete sidelined for many months is something no professional employer wishes to bear and so prevention and better management of injury are essential. ${ }^{37}$ However, in this instance, it can be 'return to play' that is the key driver and not necessarily the long-term health of the athlete. Additionally, the evidence is less clear on the risk of re-injury on return to play and also how the imaging results relate to the functional capacity. Clearly, one of our roles in an elite sport is to keep the best athletes available for selection as often as possible, while also being mindful of the LTCs. However, this may be difficult in the face of managerial and financial pressures.

\section{Career-ending injuries}

The end of a sportsperson's career through injury is regrettable at whatever stage they might be: whether this is a talented youngster or a veteran athlete. It should be one of our duties in sports medicine to help identify the most common of these injuries and help prevent them through better coaching, conditioning or injury management, or to help advise those who regulate the sport on how to make it safer. These injuries may be acute catastrophic injuries or accumulated trauma. 
In the example of anterior cruciate ligament rupture, it is usually the consequent articular cartilage injuries that lead to the premature end of an athlete's career, rather than the instability of the knee. ${ }^{38}$ For the athlete, there is a massive sense of loss; a lack of a career fulfilled or hopes dashed. There may be financial compensation through insurance schemes, but this is not the case in all sports. In some countries, data from insurance schemes can help identify the most common causes of medical retirement from a sport. ${ }^{39}$ Can we prevent other athletes from developing the same problems? Unfortunately, the lack of data appears to be partly a result of a lack of investment in sports medicine research. If long-term follow-up on retired athletes by each sport became mandatory, then the funding would have to be made available.

\section{Long-term consequences}

We enter into a sport fear-free and for the enjoyment that it brings us. We do not consider the potential hazards and the possible lifechanging possibilities that may lie in wait. In 1980, at the age of 24, I incurred an incomplete tetraplegia from a rugby tackle that would affect and shape the rest of my life. The year I spent in rehabilitation in the spinal injuries unit it led me to meet 10 other people also injured that year with a similar injury. The prevalence of spinal injury at this time prompted an examination of the laws of the game and I joined the newly created Rugby Football Union Injuries Working Party that helped bring about recognition of the issue, a change in the laws and subsequently an Injured Players Fund to help support those injured in the sport. ${ }^{4,40}$ But catastrophic injury is not the only important factor. Long-term participation in physical activity is necessary for health maintenance. ${ }^{4}$ We cannot store up the health benefits of an active early life; it has to be lifelong. Injury acquired earlier in life through a sport may prevent regular physical activity later. Consequently, the prevention and better treatment of injuries that limit physical activity in the long-term are essential so that we can remain active in later life. The risk of participation in a sport needs to consider the potential impact on the future health also.

\section{Training volume}

Generally, the higher the level of performance, the higher the level of participation, but many enthusiastic amateurs also have high levels of participation without high skill level. We are typically weak in sports medicine at documenting the risk of injury per hours of training and competition to understand the relative risk of participation in different sports. ${ }^{41}$ Sudden changes in the volume of training have been associated with certain overuse injuries which may be more important than the total volume of training in certain activities, and this may be sport-specific. We need to understand these relationships more clearly to attribute injury risk. In wheelchair racing, for example, there did not appear to be any difference in the frequency of injury between elite and non-elite athletes. ${ }^{42}$ The training variables of the distance pushed per week, the number of weight training sessions, or the length of time the athlete had been involved in wheelchair racing, were not associated with an increased risk of injury. High levels of participation in a sport may not be the risk factor but the history of how you reached that level may be.

\section{Co-existing impairment}

Co-existing impairments may be a contributory factor in injury risk and paralympic athletes are a prime example of this. We need to ensure that such data are not misleading. In several studies of injury in paralympic athletes, the subjects have been classed as 'wheelchair athletes.' ${ }^{43,44}$ This can be a confusing terminology for assessing the injury risk from a prevention perspective. First, many wheelchair sports are technically and biomechanically quite different despite using a wheelchair for the sport; for example, wheelchair racing versus wheelchair basketball versus wheelchair fencing. Second, within each sport, there may be different levels of impairment type; for example, spinal cord injury or a mixture of impairment types competing in the same sport. There may also be, for example, an amputee athlete who walks unaided with a prosthesis but removes it to participate in their sport in a wheelchair. Finally, there are those athletes who use a wheelchair for daily mobility but come out of the wheelchair for sport participation; for example, swimming or powerlifting. In these cases, the specificity of the impairment type and sport is essential to truly understand the risk factors and prevention strategies.

\section{Summary}

By using an approach that considers all these factors, we can start to develop models of the understanding of injury risk at different life phases and the levels of participation in a specific sport. In this way, when we talk about the risk inherent in sport participation, it is relevant to the particular sport, the level of participation, skill, age and the potential future health consequences.

It poses the following questions for sports physicians, healthcare providers and educators generally and for the governing bodies of sports to address in a systematic fashion. Each sport will generate its own model based upon the following:

- What are the most common injuries that occur in the sport:

- during growth and development

- in athletes new to the sport (SAIs)

- in experienced competitive athletes?

- What are the most common career-ending injuries?

- What are the long-term health consequences of participation in the sport?

- Is the pattern of injuries the same in elite and recreational athletes for each of the above?

The key aspect of this approach is that we try to determine the significant injury issues over the individuals' lifetime participation in a sport that allows us to define the areas of further detailed research as outlined by Meeuwisse. ${ }^{16}$ Each sport model will include these variables but the timeline will be specific to the sport. For example, the time profile of gymnastics would be very different to distance running. In this way, each sport would develop an ongoing process of evaluation of these questions (Fig. 1) that would influence coach

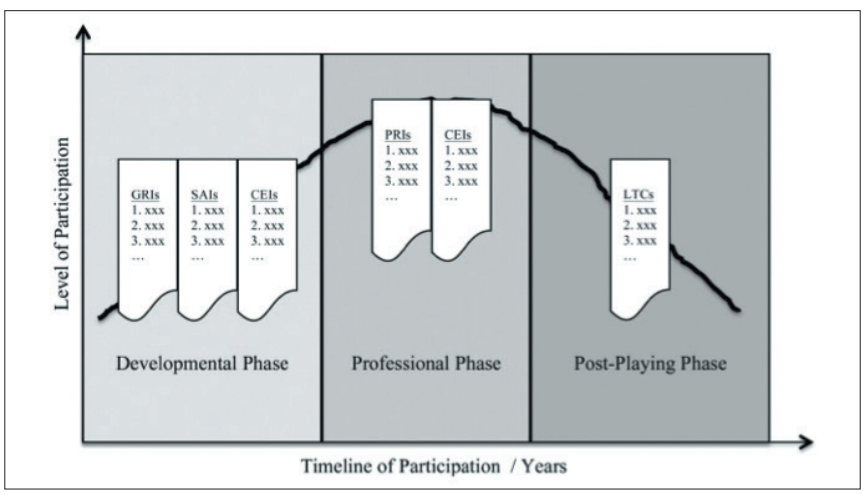

Fig. 1. Possible sport model showing frequency tables of injuries by type over the timeline of participation. 
education, training principles, equipment factors and management strategies based upon the targeted need. Improving safety in a sport can then be monitored on a systematic basis.

Published epidemiological studies show that our knowledge is generally patchy and quite variable across different sports. ${ }^{41,45}$ As a member of a working party and the co-author of one effort to make sport safer in the UK, I was disappointed that despite the importance of the issue, most of the recommendations were not adopted. ${ }^{46}$ It can be a lack of political will or funding that stops these issues being taken seriously and carried forward. As a sports medicine community, as a medical community and as a community generally, we need to address these issues in a structured and proactive way for the greater good before we are forced into defensive actions by a litigious society. Sport is wonderful, sport is inspiring and sport is liberating but it can result in significant harm to health. Let us commit to making it safer through collaboration, organised research and working with governing bodies rather than by legal process.

It is interesting to consider the text on a website with regard to mesothelioma: 'being exposed to asbestos is not your fault. You may have been put in harm's way because of a previous job, a careless employer, or a negligent manufacturing company. ${ }^{37}$ So experiencing the consequences some years after professional sport participation may not limit the employer's liability if inadequate precautions were taken. Did the employer assess the risks of sport participation? Did they provide appropriate information? Did they take adequate preventive measures? Interestingly, a Google search for 'mesothelioma lawyer' brought 436000 results but more alarmingly a search for 'sports injury lawyer' brought a massive 1040000 results.

It is likely that we will see an increasing number of litigation cases seeking compensation for long-term health problems from sports injury. The full extent of the impact on health may not necessarily have been evident at the time of leaving the sport. Will professional athletes who develop long-term health consequences from sport participation, without prior warning of the risks, become the industrial disease claimants of the future? Will it be litigation that pushes forward sports injury surveillance or should we be proactive in adopting new models that produce greater clarity of the issues and guidance on how to resolve them?

To prevent this, we must encourage sports governing bodies to take a lead in establishing a lifetime model of the injury occurrence, in professional and amateur levels, specific for their sport. Sports medicine researchers must work with them to look at causation, prevention, management and long-term health as an ongoing process with a continued drive to reduce the incidence and severity of injury. Once a sport-specific model is established, there can be improved guidance for coaches and healthcare professionals, but moreover the governing body, as an employer, will be meeting its requirements for professional sport and also meeting its ethical responsibility.

Acknowledgments. The author thanks Dr Polly Baker and Stephanie Anderson for proof-reading, comments and encouragement.

\section{Competing interests. None.}

Provenance and peer review. Not commissioned; externally peer reviewed.

\section{References}

1. Marshall SW, Guskiewicz KM. Sports and recreational injury: The hidden cost of a healthy lifestyle. Inj Prev 2003;9:100-102.
2. Conn JM, Annest JL, Gilchrist J. Sports and recreation related injury episodes in the US population, 1997-99. Inj Prev 2003;9:117-123.

3. Department for Culture, Media and Sport/Strategy Unit. Game Plan: A Strategy for Delivering Government's Sport and Physical Activity Objectives. London: Department for Culture, Media and Sport/Strategy Unit, 2002.

4. Department Of Health. At Least Five a Week: Evidence on the Impact of Physical Activity and its Relationship to Health. London: Department Of Health, 2004.

5. Shephard RJ. Can we afford to exercise, given current injury rates? Inj Prev 2003;9:99100 .

6. Treisman GJ, Clark MR. A behaviorist perspective. Adv Psychosom Med 2011;30:8-21.

7. Podlog L, Dimmock J, Miller J. A review of return to sport concerns following injury rehabilitation: practitioner strategies for enhancing recovery outcomes. Phys Ther Sport 2011;12:36-42.

8. Bianco T, Malo S, Orlick T. Sport injury and illness: elite skiers describe their experiences. Res Q Exerc Sport 1999;70:157-169.

9. ALARP "At A Glance". http://www.hse.gov.uk/risk/theory/alarpglance.htm (accessed 6 July 2011)

10. Lohmander LS, Ostenberg A, Englund M, et al. High prevalence of knee osteoarthritis, pain, and functional limitations in female soccer players twelve years after anterior cruciate ligament injury. Arthritis Rheum 2004;50:3145-3152.

11. von Porat A, Roos EM, Roos H. High prevalence of osteoarthritis 14 years after an anterior cruciate ligament tear in male soccer players: a study of radiographic and patient relevant outcomes. Ann Rheum Dis 2004;63:269-273.

12. Roos H. Are there long-term sequelae from soccer? Clin Sports Med 1998;17:819-31, viii.

13. Roos H, Lindberg H, Gärdsell P, et al. The prevalence of gonarthrosis and its relation to meniscectomy in former soccer players. Am J Sports Med 1994;22:219-222.

14. Lindberg H, Roos H, Gärdsell P. Prevalence of coxarthrosis in former soccer players. 286 players compared with matched controls. Acta Orthop Scand 1993;64:165-167.

15. van Mechelen W, Hlobil H, Kemper HC. Incidence, severity, aetiology and prevention of sports injuries. A review of concepts. Sports Med 1992;14:82-99.

16. Meeuwisse WH, Tyreman H, Hagel B, et al. A dynamic model of etiology in sport injury: the recursive nature of risk and causation. Clin J Sport Med 2007;17:215-219.

17. Meeuwisse WH. Assessing causation in sport injury: a multifactorial model. Clin J Sport Med 1994;4:166-170.

18. Hägglund $M$, Waldén $M, B a h r ~ R$, et al. Methods for epidemiological study of injuries to professional football players: developing the UEFA model. Br J Sports Med 2005;39:340346

19. Ekstrand J, Hägglund M, Waldén M. Injury incidence and injury patterns in professional football: the UEFA injury study. Br J Sports Med 2011;45:553-538.

20. Hägglund M, Waldén M, Ekstrand J. UEFA injury study-an injury audit of European Championships 2006 to 2008. Br J Sports Med 2009;43:483-489.

21. Brooks JH, Kemp SP. Injury-prevention priorities according to playing position in professional rugby union players. Br J Sports Med 2011;45:765-775.

22. Sankey RA, Brooks JH, Kemp SP, et al. The epidemiology of ankle injuries in professional rugby union players. Am J Sports Med 2008;36:2415-2424.

23. Fuller CW, Ashton T, Brooks JH, et al. Injury risks associated with tackling in rugby union. Br J Sports Med 2010;44:159-167.

24. Kemp SP, Hudson Z, Brooks JH, et al. The epidemiology of head injuries in English professional rugby union. Clin J Sport Med 2008;18:227-234

25. Brooks JH, Fuller CW, Kemp SP, et al. Incidence, risk, and prevention of hamstring muscle injuries in professional rugby union. Am J Sports Med 2006;34:1297-1306.

26. Roos H. Increased risk of knee and hip arthrosis among elite athletes. Lower level exercise and sports seem to be "harmless". Lakartidningen 1998;95:4606-4610.

27. Caine DJ, Golightly YM. Osteoarthritis as an outcome of paediatric sport: An epidemiological perspective. Br J Sports Med 2011;45:298-303

28. Maffulli N, Waterston SW, Squair J, et al. Changing incidence of Achilles tendon rupture in Scotland: a 15-year study. Clin J Sport Med 1999;9:157:60.

29. Hrysomallis C. Hip adductors' strength, fl exibility, and injury risk. J Strength Cond Res 2009:23:1514-1517.

30. Luukinen H, Koski K, Laippala P, et al. Factors predicting fractures during falling impacts among home-dwelling older adults. J Am Geriatr Soc 1997;45:1302-1309.

31. Giles KB. Injury resilience - let's control what can be controlled! Br J Sports Med 2011;45:684-685.

32. Kitai E, Itay S, Ruder A, et al. An epidemiological study of lateral epicondylitis (tennis elbow) in amateur male players. Ann Chir Main 1986;5:113-121.

33. Dennis RJ, Finch CF, McIntosh AS, et al. Use of field-based tests to identify risk factor for injury to fast bowlers in cricket. Br J Sports Med 2008;42:477-482.

34. Glazier PS. Is the 'crunch factor' an important consideration in the aetiology of lumbar spine pathology in cricket fast bowlers? Sports Med 2010;40:809-815.

35. Orchard JW, James T, Portus M, et al. Fast bowlers in cricket demonstrate up to 3- to 4-week delay between high workloads and increased risk of injury. Am J Sports Med 2009;37:1186-1192. 
36. Portus M, Mason BR, Elliott BC, et al. Technique factors related to ball release speed and trunk injuries in high performance cricket fast bowlers. Sports Biomech 2004;3:263-284

37. Orchard JW. On the value of team medical staff: can the "Moneyball" approach be applied to injuries in professional football? Br J Sports Med 2009;43:963-965.

38. Myklebust G, Holm I, Maehlum S, et al. Clinical, functional, and radiologic outcome in team handball players 6 to 11 years after anterior cruciate ligament injury: A follow-up study. Am J Sports Med 2003;31:981-989.

39. Roos H, Ornell M, Gärdsell P, et al. Soccer after anterior cruciate ligament injury-an incompatible combination? A national survey of incidence and risk factors and a 7-year follow-up of 310 players. Acta Orthop Scand 1995;66:107-112.

40. Webborn ADJ. Rugby Injuries Study, Pilot Scheme: Rugby Fotball Union, 1985.
41. Caine DJ, Harmer PA, Schiff MA. Epidemiology of Injury in Olympic Sports. West Sussex: Wiley-Blackwell 2010

42. Taylor D, Williams T. Sports injuries in athletes with disabilities: Wheelchair racing. Paraplegia 1995;33:296-299.

43. Curtis KA, Dillon DA. Survey of wheelchair athletic injuries: common patterns and prevention. Paraplegia 1985;23:170-175.

44. Ferrara MS, Davis RW. Injuries to elite wheelchair athletes. Paraplegia 1990;28:335-41.

45. Murphy DF, Connolly DA, Beynnon BD. Risk factors for lower extremity injury: A review of the literature. Br J Sports Med 2003;37:13-29.

46. Department Of Culture, Media \& Sport. Sport in the UK - Improving Safety and Medical Provision, 2002

47. Your Legal Rights And Options. http://www.mesolawsuit.com (accessed 7 July 2011). 